\title{
International Prognostic Index
}

National Cancer Institute

\section{Source}

National Cancer Institute. International Prognostic Index. NCI Thesaurus. Code C20118.

A list of five factors that help doctors assess how a non-Hodgkin lymphoma patient might respond to a certain treatment or predict the risk of disease recurrence and survival following therapy. The factors are: 1) patient's age, 2) stage of disease: an indication of how localized or widespread is the disease, 3) LDH levels: serum levels often correlate with the amount of tumor in the body, 4) the number of extranodal, nonlymphatic sites found, 5) the patient's overall health. (from Lymphoma Research Foundation of America glossary (www.lymphoma.org)) 